\title{
The Reform of Incentive Mechanism for Second Major Program: Based on the Principal-Agent Theory
}

\author{
Guangtao Xia ${ }^{1}$, , Wangyin $\mathrm{Hu}^{2}$, Hao Wang ${ }^{3}$ \\ ${ }^{1}$ PBC School of Finance, Tsinghua University, Beijing, P. R. China \\ ${ }^{2}$ School of Social Sciences, Tsinghua University, Beijing, P. R. China \\ ${ }^{3}$ School of Economics and Management, Tsinghua University, Beijing, P. R. China \\ Email address: \\ xiagt@pbcsf.tsinghua.edu.cn (Guangtao Xia) \\ ${ }^{*}$ Corresponding author
}

To cite this article:

Guangtao Xia, Wangyin Hu, Hao Wang. The Reform of Incentive Mechanism for Second Major Program: Based on the Principal-Agent Theory. Education Journal. Vol. 8, No. 6, 2019, pp. 332-337. doi: 10.11648/j.edu.20190806.24

Received: October 24, 2019; Accepted: November 22, 2019; Published: December 3, 2019

\begin{abstract}
Over the past three decades, many universities in China provide students with the Second Major program, aiming at cultivating interdisciplinary talents and meeting the undergraduates' increasing demands for a wide variety of knowledge. In general, the Admissions Committee often attaches importance to the applicants' previous academic records rather than their willingness to study during the process of selection, which tends to result in the adverse selection problem. Besides, as the Second Major education system fails to incorporate an appropriate incentive compatible mechanism, many enrolled students with low level of learning initiative would be prone to moral hazard problems, such as truancy, chronic absence and poor performance in class. In order to solve the above two kinds of problems and improve the quality of education, we first propose a novel pricing strategy bundling tuition fees and course quantities based on the principal-agent theory, which is designed to mitigate the adverse selection problem by identifying applicants' private information (the level of their willingness to study) and enable the Admissions Committee to select those applicants with both strong academic ability and high learning willingness. Then we set up the incentive models for the full and limited liability scholarship systems respectively to address the moral hazard problems, and find that the infeasible full liability scholarship system can simultaneously optimize the utility of all participants, while the feasible limited liability scholarship system would only bring about the sub-optimal results.
\end{abstract}

Keywords: Incentive Mechanism, Second Major Program, Principal-Agent Theory, Adverse Selection, Moral Hazard

\section{Introduction}

With the extensive demand for interdisciplinary talents in various fields of society, more and more universities begin to set up Second Major programs, and pursuing a second major has become a way for college students to expand the breadth of knowledge and improve their own abilities. However, in the process of implementing the Second Major programs, several problems are increasingly prominent.

First of all, in the application stage of the Second Major programs, the organizer only cares for the applicants' GPA to ensure their capacities, but not for their interests and willingness-to-pay for study. There existed a weird phenomenon that applicants with low level of study initiative rather than those with high level have more opportunities to be accepted into a second major program, which is called "adverse selection". Secondly, after enrolled in the Second Major program, many students show a perfunctory attitude towards the second major courses, which goes against the original intention of the state and universities to set up the Second Major programs, namely the problem of "moral hazard".

In fact, "adverse selection" and "moral hazard" are two important research directions of "principal-agent" theory. "Principal-agent" theory originates from contract theory and is one of the most important development fields of microeconomic theory in the past 30 years. It mainly studies how the principal can motivate the agent's behavior through mechanism design to achieve the desired result when there is information asymmetry and interests conflict between two 
parties [1-4]. The principal-agent theory originated in the early 1970 s when some talented economists paid attention to the problems of enterprises' internal information asymmetry and incentive incompatibility [5-7]. Up to now, this theory has been widely applied in the studies of mechanism design, financial markets, corporate governance, administrative management, property rights and other fields [8-14].

In terms of the educational field, there are also a large number of scholars who use the "principal-agent" theory to study education-related issues, mainly focusing on educational governance, agency costs, and the complex multi-party relationship in the education system [15-17]. Specifically, an important paper discussed the dual multi-layer principal-agent relationships in China's education system and pointed out the existing problems in education, such as the waste of educational resources, low efficiency and unsatisfactory effects from the perspective of the information asymmetry between related principals and agents [18]. In addition, two Chinese researchers conducted a welfare analysis on the issue of "charged private tutoring of in-service teachers" based on principal-agent theory, and put forward the "low frequency regulation" and "high violation cost" collocation mode to reduce the regulatory costs [19]. Besides, another interesting research focused on the information asymmetry problem between family and school in the education chain, and proposed a set of solutions based on the "principal-agent" theory to promote the synergy between family education and school education [20].

However, as far as the available literature is concerned, there are relatively few theoretical studies on the enrollment mechanism and implementation effects of the Second Major programs, especially the analysis based on principal-agent theory. However, the problems of "adverse selection" and "moral hazard" in the current Second Major programs are obviously not conducive to the realization of the origin benign goals of these programs, and will also result in deadweight welfare loss. In this regards, it's meaningful to conduct deep research on this issue. Through investigation, we found that an important institutional factor contributing to these problems is that "the current enrollment selection mechanism does not fully consider applicants' willingness to study". The current pre-screening mechanism and post-incentive mechanism, only focuses on whether students have the ability to study, but ignores their interests in the second majors and their willingness to work hard. However, the final cultivation effect of the Second Major programs severely depends on the devotion and efforts of enrolled students. Students with high study ability but low level of learning initiative are more likely to have a perfunctory learning attitude, which is a great waste of educational resources. Only students with high willingness to study will intend to pay more time and efforts into the Second Major program, which is very important to ensure the quality of study.

To make up for the research gaps and solve the "adverse selection" and "moral hazard" problems existing in the current Second Major program, this paper designs a charging mechanism with the combining of tuition fees and course quantities for the Second Major program based on the "Price-Quantity-Bundle" strategy in nonlinear pricing model. Through inducing applicants to make ex-ante self-selection, we can identify their private information (willingness of study) and select those students with high level of learning willingness to acquire interdisciplinary knowledge. In addition, for students with low level of study initiative, we also provides them with a weakened "Tuition Fee-Course Quantity" option, so as to avoid crowding-out effect and moral hazard problems.

\section{The Charging Mechanism Bundling Tuition Fees and Course Quantity}

In the selection stage of the Second Major programs, applicants' willingness to study should be fully considered. However, applicants' willingness is personal information, which cannot be directly observed by the selectors. Fortunately, students' willingness to study is often positively correlated with their willingness to pay. In general, the higher their willingness, the more money they are willing to pay. Therefore, the selectors can design a charging mechanism to identify the applicants' willingness to study through "self-selection".

\subsection{Assumptions}

For the applicants of the Second Major programs, we proposes the following four hypotheses.

Firstly, the applicants are rational people who seek to maximize their own utility;

Secondly, applicants have private information, namely willingness to study, which can be divided into two different types: high-intention students (H-type) and low-intention students (L-type), whose distribution ratio is respectively $P_{H}$ and $P_{L}$;

Thirdly, the applicants are homogeneous, and their preferences are unsaturated, that is, applicants always tend to get more courses when the costs of tuition are the same.

Fourthly, the utility of unit currency is the same for every applicant. The applicant's willingness to pay is only determined by the willingness to study.

At the same time, the selection side of the Second Major programs also has the following three important characteristics:

First, the selectors are rational people, and they pursue the maximization of expected utility;

Second, the utility function of the selection side is composed of two parts. One part is the financial income, that is, the tuition income minus the operating cost. The other part is the benefit of education, that is, the cultivation effect of the Second Major program, namely the quality of enrolled students' study;

Third, the selectors are unable to determine the type of individual applicants, but knows their distribution. 


\subsection{Model Setup}

In order to solve the problem of adverse selection in the Second Major program, we design a charging mechanism bundling "Tuition Fee" and "Course Quantity", which can be noted by (F, Q), where F represents the one-time tuition fee charged by the school and Q denotes the quantity of courses included in the program. For the convenience of discussion, this paper assumes that there are only two types of applicants. Therefore, there are two types of charging schemes : $\left(F_{H}, Q_{H}\right)$ and $\left(F_{L}, Q_{L}\right)$, wherein $F_{H}>F_{L} \geq 0, Q_{H}>Q_{L} \geq 0$. The goal of the selection side is to identify the individual study intentions of applicants through the design of the charging mechanism, that is, applicants with high study intentions choose $\left(F_{H}, Q_{H}\right)$ and applicants with low study intentions choose $\left(F_{L}, Q_{L}\right)$, so as to maximize their expected utility.

Considering the utility function of the applicant, the variables that affect the utility of the applicant mainly include the tuition fee F and the quantity of courses Q. F is the cost of the applicants, while $\mathrm{Q}$ is their benefit. Therefore, the utility function of the applicant is:

$$
U_{i}\left(F_{i}, Q_{i}\right)=f\left(Q_{i}\right)-g\left(F_{i}\right), i=H, L
$$

Where $f\left(Q_{i}\right)$ and $g\left(F_{i}\right)$ respectively represents the revenue utility function and cost utility function. For the convenience of calculation, this paper assumes that the utility function is in linear form:

$$
\mathrm{U}_{i}\left(F_{i}, Q_{i}\right)=X_{i} \cdot Q_{i}-F_{i}, i=H, L
$$

Where $X_{i}$ represents the expected average score of all courses in different types of students. Since it is assumed that the course performance is only related to the degree of efforts, and the degree of efforts is largely determined by the willingness to study, it can be concluded that students with high willingness also expect higher grades, i.e. $X_{H}>X_{L}$.

Considering the expected utility function of the selection side, it includes two parts, educational income and financial income. The former part can be understood as the sense of achievement gained by fostering outstanding talents, so it is related to the applicants' performance on their second major courses. At the same time, the later part, namely the tuition fees paid by the applicants, will also enhance the utility. Therefore, the total expected utility function of the selectors can be expressed as:

$$
\mathrm{U}=\sum_{i} \mathrm{~N} \cdot \mathrm{P}_{\mathrm{i}} \cdot X_{i} \cdot Q_{i}+\sum_{i} \mathrm{~N} \cdot \mathrm{P}_{\mathrm{i}} \cdot F_{i}-C(q), i=H, L
$$

Where $\mathrm{N}$ represents the number of students enrolled in the Second Major program, $\mathrm{P}_{\mathrm{i}}$ is the distribution proportion of different types of applicants, $\mathrm{q}$ is the total quantity of courses offered by the program, and $\mathrm{C}(\mathrm{q})$ is the cost function of the selector. Due to limited educational resources, $\mathrm{C}(\mathrm{q})$ is assumed to be convex, and satisfies the condition of increasing marginal cost. In order to simplify the calculation, we assume $C(q)=q^{2}$ and $N=1$, then

$$
\mathrm{C}(\mathrm{q})=\left(P_{H} \cdot Q_{H}+P_{L} \cdot Q_{L}\right)^{2}
$$

Rearranging the expected utility function of the selectors, we can obtain:

$$
\mathrm{U}=\sum_{i} \mathrm{P}_{\mathrm{i}}\left(X_{i} \cdot Q_{i}+F_{i}\right)-C(q)
$$

In addition, mechanism design must satisfy Individual Rationality Constraint and Incentive Compatibility Constraint. In our setup, the individual rationality constraint requires the expected utility function of the applicant to be no less than 0 .

$$
\begin{aligned}
& \mathrm{IR}_{1}: \mathrm{U}_{L}\left(F_{L}, Q_{L}\right) \geq 0 \\
& \mathrm{IR}_{2}: \mathrm{U}_{H}\left(F_{H}, Q_{H}\right) \geq 0
\end{aligned}
$$

On the other hand, the incentive compatibility constraint ensures that the applicants would make the optimal choices according to their private information.

$$
\begin{array}{cc}
I C_{1}: U_{L}\left(F_{L},\right. & \left.Q_{L}\right) \geq U_{L}\left(F_{H}, Q_{H}\right) \\
I C_{2}: U_{H}\left(F_{H},\right. & \left.Q_{H}\right) \geq U_{H}\left(F_{L}, Q_{L}\right)
\end{array}
$$

Under the condition of individual rationality constraint and incentive compatibility constraint, the selection side pursues the maximization of expected utility, so the problem can be expressed as follows.

$$
\operatorname{Max}\left\{U=\sum_{i \in\{H, L\}} P_{i} \cdot\left(X_{i} \cdot Q_{i}+F_{i}\right)-C(q)\right\}
$$

s.t.

$$
\begin{gathered}
I R_{1}: U_{L}\left(F_{L}, Q_{L}\right) \geq 0 \\
I R_{2}: U_{H}\left(F_{H}, Q_{H}\right) \geq 0 \\
I C_{1}: U_{L}\left(F_{L}, Q_{L}\right) \geq U_{L}\left(F_{H}, Q_{H}\right) \\
I C_{2}: U_{H}\left(F_{H}, Q_{H}\right) \geq U_{H}\left(F_{L}, Q_{L}\right)
\end{gathered}
$$

\subsection{Solving the Model}

By substituting in the specific function, the model is organized as follows:

$$
\begin{aligned}
\operatorname{Max}\{U= & P_{H} \cdot\left(X_{H} \cdot Q_{H}+F_{H}\right)+P_{L} \cdot\left(X_{L} \cdot Q_{L}+F_{L}\right)- \\
& \left.\left(P_{H} \cdot Q_{H}+P_{L} \cdot Q_{L}\right)^{2}\right\}
\end{aligned}
$$

s.t.

$$
\begin{gathered}
I R_{1}: X_{L} \cdot Q_{L}-F_{L} \geq 0 \\
I R_{2}: X_{H} \cdot Q_{H}-F_{H} \geq 0 \\
I C_{1}: X_{L} \cdot Q_{L}-F_{L} \geq X_{L} \cdot Q_{H}-F_{H} \\
I C_{2}: X_{H} \cdot Q_{H}-F_{H} \geq X_{H} \cdot Q_{L}-F_{L}
\end{gathered}
$$

Given $X_{H}>X_{L}$, we have $X_{H} \cdot Q_{H}-F_{H} \geq X_{H} \cdot Q_{L}-F_{L}>$ $X_{L} \cdot Q_{L}-F_{L} \geq 0$. Therefore, the condition $\mathrm{IR}_{2}$ can be eliminated, and the condition $\mathrm{IR}_{1}$ must satisfy the equality constraint, namely $X_{L} \cdot Q_{L}=F_{L}$. Thus, the maximization problem is transformed into: 


$$
\operatorname{Max}\left\{U=P_{H} \cdot\left(X_{H} \cdot Q_{H}+F_{H}\right)+2 P_{L} \cdot X_{L} \cdot Q_{L}-\left(P_{H} \cdot Q_{H}+\right.\right.
$$

s.t.

$$
\begin{gathered}
F_{H}-X_{L} \cdot Q_{H} \geq 0 \\
X_{H} \cdot Q_{H}+\left(X_{L}-X_{H}\right) \cdot Q_{L}-F_{H} \geq 0
\end{gathered}
$$

So we have the Lagrangian function of the above problem, $\mathcal{L}=\mathrm{P}_{\mathrm{H}} \cdot X_{H} \cdot Q_{H}+\mathrm{P}_{\mathrm{H}} \cdot F_{H}+2 \mathrm{P}_{\mathrm{L}} \cdot X_{\mathrm{L}} \cdot Q_{L}-\left(\mathrm{P}_{\mathrm{H}} \cdot \mathrm{Q}_{\mathrm{H}}+\mathrm{P}_{\mathrm{L}} \cdot\right.$ $\left.Q_{\mathrm{L}}\right)^{2}+\lambda_{1}\left(F_{H}-X_{L} \cdot Q_{H}\right)+\lambda_{2}\left(X_{H} \cdot Q_{H}+\left(X_{L}-X_{H}\right) \cdot Q_{L}-\right.$ $\left.F_{H}\right)$.

The Kuhn-Tucker conditions are as follows:

$$
\begin{aligned}
& \frac{\partial \mathcal{L}}{\partial Q_{H}} \leq 0, \quad Q_{H} \geq 0 \text { and } Q_{H} \cdot \frac{\partial \mathcal{L}}{\partial Q_{H}}=0 \\
& \frac{\partial \mathcal{L}}{\partial Q_{L}} \leq 0, \quad Q_{L} \geq 0 \text { and } Q_{L} \cdot \frac{\partial \mathcal{L}}{\partial Q_{L}}=0 \\
& \frac{\partial \mathcal{L}}{\partial F_{H}} \leq 0, \quad F_{H} \geq 0 \text { and } F_{H} \cdot \frac{\partial \mathcal{L}}{\partial F_{H}}=0 \\
& \frac{\partial \mathcal{L}}{\partial \lambda_{1}} \geq 0, \lambda_{1} \leq 0 \text { and } \lambda_{1} \cdot \frac{\partial \mathcal{L}}{\partial \lambda_{1}}=0 \\
& \frac{\partial \mathcal{L}}{\partial \lambda_{2}} \geq 0, \lambda_{2} \leq 0 \text { and } \lambda_{2} \cdot \frac{\partial \mathcal{L}}{\partial \lambda_{2}}=0
\end{aligned}
$$

We can obtain the explicit solution $Q_{H}{ }^{*}=\frac{X_{H}}{\mathrm{P}_{\mathrm{H}}}, F_{H}{ }^{*}=$ $\frac{X_{H}{ }^{2}}{\mathrm{P}_{\mathrm{H}}} ; Q_{L}{ }^{*}=\frac{X_{L}}{\mathrm{P}_{\mathrm{L}}}, \quad F_{L}^{*}=\frac{X_{L}{ }^{2}}{\mathrm{P}_{\mathrm{L}}}$.

Therefore, the charging mechanism of the selection side should be set accordingly as $\left(F_{H}{ }^{*}=\frac{X_{H}{ }^{2}}{\mathrm{P}_{\mathrm{H}}}, Q_{H}{ }^{*}=\frac{X_{H}}{\mathrm{P}_{\mathrm{H}}}\right)$ and $\left(F_{L}{ }^{*}=\frac{X_{L}{ }^{2}}{\mathrm{P}_{\mathrm{L}}}, Q_{L}{ }^{*}=\frac{X_{L}}{\mathrm{P}_{\mathrm{L}}}\right)$. Under this condition, H-type students with high level of study initiative should optimally choose high-requirement scheme $\left(\frac{X_{H}{ }^{2}}{\mathrm{P}_{\mathrm{H}}}, \frac{X_{H}}{\mathrm{P}_{\mathrm{H}}}\right)$, while L-type students would choose low-requirement scheme $\left(\frac{X_{L}{ }^{2}}{\mathrm{P}_{\mathrm{L}}}, \frac{X_{L}}{\mathrm{P}_{\mathrm{L}}}\right)$.

\section{The Scholarship Incentive Mechanism}

Indeed, under the charging mechanism bundling "Tuition Fee" and "Course Quantity", the applicants with private information (willingness to take courses) would make optimal decisions by themselves, then the selectors can identify applicants' willingness to work hard accordingly, which helps to solve the problem of adverse selection. However, when applicants start to take courses, the charging mechanism cannot guarantee the quality of the process alone, and moral hazard problem will inevitably occurs. Therefore, in this part, the scholarship model is introduced to solve the problem of moral hazard by encouraging enrolled students to complete the courses with high quality.

\subsection{Assumptions}

In this model, we assume the variable $e$ as the indicator of students' behavior, wherein $\mathrm{e}=1$ represents that student pay enough efforts on the project, and $\mathrm{e}=0$ represents no efforts correspondingly. And as private information, students' behavior cannot be observed by others. We also assume there is cost when students pay their own efforts. The cost function is $\mathrm{y}(e)$, where $\mathrm{y}(\mathrm{e}=1)=\mathrm{C}, \mathrm{y}(\mathrm{e}=0)=0$. And payoff from efforts are uncertain, students may either get high scores $(\mathrm{x}=\mathrm{H})$ or low scores $(\mathrm{x}=\mathrm{L})$. It is also possible for students to get high grades without working hard, but the probability of this case $\operatorname{Pr}(\mathrm{x}=\mathrm{H} \mid \mathrm{e}=0)=\mathrm{q}$, is lower than that of working hard, $\operatorname{Pr}(\mathrm{x}=\mathrm{H} \mid \mathrm{e}=1)=\mathrm{p}$, namely $0<\mathrm{q}<\mathrm{p}<1$. In general, the expected benefit of paying efforts is greater than that of no effort, namely $p H+(1-p) L-C>q H+(1-$ q) $L$.

In addition, students are risk-averse and can get scholarships according to their own achievements and also pay corresponding costs. So their utility function is $\mathrm{V}(\mathrm{x})=$ $\mathrm{U}(\mathrm{t}(\mathrm{x}))-\mathrm{y}(\mathrm{e})$, where $\mathrm{U}(\cdot)$ is a strictly increasing concave function. The reservation utility of students is 0 , namely the utility of students without scholarships will be 0 . Furthermore, the school is risk neutral and can only observe the final results of enrolled students.

\subsection{Model Setup}

For the school, the fundamental purpose is to encourage enrolled students to pay more efforts and achieve good academic results. However, whether making efforts or not cannot be observed by the school, thus the level of students' efforts can only be evaluated by their grades. Therefore, the school encourages students to make enough efforts through the scholarship system, granting different levels of scholarships to excellent students according to their academic performance. The school's utility function includes two parts, student achievement and scholarship expenditure. And the utility of the school is positively related to the students' achievements, but negatively related to the scholarship expenditures. Therefore, we model the school's utility function as $W(x)=x-t(x)$, where $\mathrm{x}$ represents students' performance, and $\mathrm{t}(\mathrm{x})$ represents scholarship expenditures.

We define the concrete utility function of the school as $\operatorname{Max}\{p(H-t(H))+(1-p)(L-t(L))\}$, which means the school pursues its own utility maximization under the condition of uncertainty when designing a scholarship.

The utility of students also includes two parts: firstly, students can derive positive utility from getting scholarships; secondly, students also pay corresponding costs due to their efforts paid to achieve good academic performance, so their utility function can be defined as $\mathrm{V}(\mathrm{x})=\mathrm{U}(\mathrm{t}(\mathrm{x}))-\mathrm{y}(\mathrm{e})$, where $\mathrm{U}(\mathrm{t}(\mathrm{x}))$ is the positive utility resulting from scholarships, and $y(e)$ is the cost of paying efforts. Students are risk averse, so $\mathrm{U}(\cdot)$ is a strictly increasing concave function.

Now consider IR constraint and IC constraint under the scholarship incentive mechanism as follows:

$$
I R: p U(t(H))+(1-p) U(t(L))-C \geq 0
$$




$$
\begin{array}{rr}
I C: p U(t(H))+(1-p) U(t(L))-C \geq q U(t(H))+ \\
(1-q) U(t(L))
\end{array}
$$

Individual rationality constraint means its utility should not be negative if students make efforts, and the incentive compatibility constraint means students can derive more utility from paying enough efforts than that case of no efforts.

\subsection{Solving the Model}

According to the above analysis, we have the following optimization problem under the above IR and IC constraints:

$$
\operatorname{Max}\{p(H-t(H))+(1-p)(L-t(L))\}
$$

For $U(\cdot)$ is a strictly increasing concave function, its inverse function can be obtained. We make $\varphi(x)=U(t(x))$, and $t(x)=U^{-1}(\varphi(x))=h(\varphi(x))$. Therefore, the maximization problem can be converted into:

$$
\begin{gathered}
\operatorname{Max}\left\{\begin{array}{c}
{[p H+(1-p) L]-[p h(\varphi(H))+} \\
(1-p) h(\varphi(L))]
\end{array}\right\} \\
I R: p \varphi(H)+(1-p) \varphi(L)-C \geq 0 \\
I C: p \varphi(H)+(1-p) \varphi(L)-C \geq \\
q \varphi(H)+(1-q) \varphi(L)-C
\end{gathered}
$$

The Lagrangian function of the above can be obtained as follows:

$$
\begin{aligned}
\mathcal{L}=[p H+ & (1-p) L]-[p h(\varphi(H))+(1-p) h(\varphi(L))] \\
& +\lambda[p \varphi(H)+(1-p) \varphi(L)-C] \\
& +\mu[(p-q)(\varphi(H)-\varphi(L))-C]
\end{aligned}
$$

The first-order condition (F.O.C) is:

$$
\begin{gathered}
-p h^{\prime}(\varphi(H))+\lambda p+\mu(p-q)=0 \\
-(1-p) h^{\prime}(\varphi(L))+\lambda(1-p)-\mu(p-q)=0
\end{gathered}
$$

So we have $\mu=\mathrm{ph}^{\prime}(\varphi(H))+(1-\mathrm{p}) h^{\prime}(\varphi(L))=$ $\frac{p}{U^{\prime}(h(\varphi(H)))}+\frac{1-p}{U^{\prime}(h(\varphi(L)))}>0$, which means individual rationality constraint is binding. And we can also get $\lambda>0$ similarly, so incentive compatibility constraint is also binding. The simultaneous equations can be expressed as follows:

$$
\begin{gathered}
I R: p \varphi(H)+(1-p) \varphi(L)-C=0 \\
I C: p \varphi(H)+(1-p) \varphi(L)-C \\
\quad=q \varphi(H)+(1-q) \varphi(L)-C
\end{gathered}
$$

Then we can obtain $\varphi(H)=\frac{1-q}{p-q} C ; \varphi(L)=-\frac{q}{p-q} C$. And as $\mathrm{h}(\cdot)$ is a monotonically increasing function, we have $t(H)=h(\varphi(H))=h\left(\frac{1-q}{p-q} C\right)>0$ and $t(L)=h(\varphi(L))=$ $h\left(-\frac{q}{p-q} C\right)<0$. Therefore, the students with high scores will be rewarded with a scholarships of $h\left(\frac{1-q}{p-q} C\right)$ and those with low scores will be punished with a "fine" of $h\left(\frac{q}{p-q} C\right)$.

However, it is obviously very difficult to enforce the punishment for students with low scores since these students may directly withdraw from the Second Major program to avoid fines. Therefore, we attempts to extend this issue in the next part and establish a limited liability scholarship model, aiming at depicting the behavior of different participants more truly and analyzing their welfare more accurately.

\subsection{Extension: Limited Liability Scholarship System}

Under the limited liability condition, the students with low scores are exempt from punishment, and their scholarship amounts are no less than zero, that is $t(L) \geq 0$. Obviously, the increase of scholarship will reduce the utility of the university. Therefore, if the low score scholarship is no less than zero, the university will definitely set it as the minimum, i.e. $t(L)=0$. So we have the reservation utility as $\varphi(L)=U(t(L))=0$. Therefore, the new maximization problem can be expressed as follows:

$$
\begin{gathered}
\operatorname{Max}\{p(H-t(H))+(1-p) L\} \\
I R: p U(t(H))-C \geq 0
\end{gathered}
$$$$
\text { IC: }(p-q) U(t(H))-C \geq 0
$$

And it's worth noting that the individual rationality constraint equation doesn't hold at this time, because individual rationality constraint and incentive compatibility constraint should hold simultaneously, then $U(t(H)) \geq \frac{c}{p-q}$ and $U(t(H)) \geq \frac{C}{p}$ should be satisfied at the same time. As the utility of the school is negatively related to the scholarship, the school will choose the minimum scholarship level that meets two constraints, namely $U(t(H))=\frac{C}{p-q}$. Then the high type scholarship can be obtained as $t(H)=U^{-1}\left(\frac{C}{p-q}\right)=h\left(\frac{C}{p-q}\right)$. Meanwhile, students will get "excess profits" under the limited liability condition, and their utility derived from making enough efforts will be $p U(t(H))-C=\frac{q}{p-q} C>0$.

Compared with the full liability case, the limited liability scholarship system have two characteristics. First, the amount of H-type scholarship for students with high scores declined, while that of the L-type scholarship increased, narrowing the gap between them. Second, the enrolled students got excess profits, while the school suffered utility loss.

\section{Conclusion}

There existed ex-ante adverse selection and ex-post moral hazard problems in the current Second Major programs. In order to solve the adverse selection problem, this paper has designed a new kind of charging mechanism bundling "Tuition Fee" and "Course Quantity" for the Second Major program, based on the principle of principal-agent theory. Through the applicants' self-selection, effective identification 
of their private information (level of learning initiative) is achieved automatically, which can mitigate the adverse selection problem.

Besides, this paper also introduced an incentive mechanism to solve the problem of moral hazard. We designed a scholarship incentive mechanism, and found that the school can encourage students to make more efforts on their study through putting forward different types of scholarships based on academic performance. What's more, we extended the benchmark model to the limited liability case, and illustrated that the infeasible full liability scholarship system with punishment mechanism can simultaneously maximize the utility of both the school and students, while the more practical limited liability scholarship system would only bring about the second-best results.

\section{References}

[1] Hölmstrom, B. (1979), "Moral hazard and observability", Bell Journal of Economics, 10 (1): 74-91.

[2] Holmstrom, B. \& Milgrom, P. (1987), "Aggregation and linearity in the provision of intertemporal incentives", Econometrica, 55 (2): 303-328.

[3] Holmstrom, B. \& Milgrom, P. (1991), "Multitask principal-agent analyses: incentive contracts, asset ownership, and job design", Journal of Law, Economics, \& Organization, 7: 24-52.

[4] Sappington, D. E. M. (1991), "Incentives in principal-agent relationships", Journal of Economic Perspectives, 5 (2): 45-66.

[5] Alchian, A. A \& Demsetz, H. (1972), "Production, Information Costs, and Economic Organization", American Economic Review, 62 (5): 777-795.

[6] Ross, S. A. (1973), "The economic theory of agency: The principal's problem", American Economic Review, 63 (2): 134-139.

[7] Jensen, M. C. \& Meckling, W. H. (1976), "Theory of the Firm: Managerial Behavior, Agency Costs and Ownership Structure", Journal of Financial Economics, 3 (4): 305-360.

[8] Kadan, O., Reny, P. J., \& Swinkels, J. M. (2017), "Existence of Optimal Mechanisms in Principal-Agent Problems", Econometrica, 85 (3): 769-823.
[9] KAMALAN, A. (2018), "Supervisory Incentives within Contracts: A Principal-Supervisor-Agent Approach", Journal of Finance, 6 (2): 58-63.

[10] Rud, O. A., Rabanal, J. P., \& Horowitz, J. (2018), "Does Competition Aggravate Moral Hazard? A Multi-Principal-Agent experiment", Journal of Financial Intermediation, 33: 115-121.

[11] Bendickson, J., Muldoon, J., Liguori, E. W., \& Davis, P. E. (2016), "Agency Theory: Background and Epistemology", Journal of Management History, 22 (4): 437-449.

[12] Rubin, J., \& Sheremeta, R. (2015), "Principal-agent Settings with Random Shocks", Management Science, 62 (4): 985-999.

[13] Maggetti, M., \& Papadopoulos, Y. (2018), "The Principalagent Framework and Independent Regulatory Agencies", Political Studies Review, 16 (3): 172-183.

[14] Bosse, D. A., \& Phillips, R. A. (2016), "Agency Theory and Bounded Self-interest", Academy of Management Review, 41 (2): 276-297.

[15] Rutherford, A., \& Meier, K. J. (2015), "Managerial Goals in a Performance-Driven System: Theory and Empirical Tests in Higher Education", Public Administration, 93 (1): 17-33.

[16] Rabossi, M. (2017), "Agency Costs in Higher Education: Evaluating an Institution through a Comprehensive Framework", Higher Education Policy, 30 (3): 319-339.

[17] Franco-Santos, M., Nalick, M., Rivera - Torres, P., \& Gomez-Mejia, L. (2017), "Governance and Well - being in Academia: Negative Consequences of Applying an Agency Theory Logic in Higher Education", British Journal of Management, 28 (4): 711-730.

[18] Li, Y. (2015), "A Discussion on the Dual Multi-Layer Principal-Agent Relationships in Education", Journal of the Chinese Society of Education, 6: 63-68.

[19] Guo, K. \& X. Gu (2016), "Why Repeated Bans on Teacher's Private Tutoring Always Fail: A Principal-agent Analysis of the Government's Regulatory Dilemma", Education \& Economy, 2: $53-60+67$

[20] Zhao, W. (2018), "Home-School Cooperation from the Perspective of Principal-Agent Theory", Teaching \& Administration, 17: 6-8. 